\title{
Assessment of Heavy Metals in Some Anti-Diabetic Medicinal Plants
}

\author{
Nasreen Fatima ${ }^{a}$, Salman Khurshid ${ }^{\mathrm{b}}$, Shazia Nisar ${ }^{\mathrm{a}}$ * \\ ${ }^{a}$ Department of Chemistry, University of Karachi, Karachi, Pakistan. \\ ${ }^{\mathrm{b}}$ Food Quality and Safety Research Institute, SARC, PARC, Karachi, Pakistan \\ *Corresponding author email: nasreenfatima@uok.edu.pk
}

\begin{abstract}
Medicinal plants are extensively used to cure diseases. However due to environmental pollution medicinal plant accumulate heavy metals which can cause adverse affect on animal and human health upon consumption. Hence chemical analysis of four heavy metals ( $\mathrm{Zn}, \mathrm{Cr}, \mathrm{Pb}$ and $\mathrm{Cd}$ ) was performed in nine medicinal plants (Adiantum capillus-veneris, Momordica charantia, Eugenia jambolana, Gymnema sylvestre, Allium sativum, Trigonella foenum-graecum, Pongamia glabra, Sphaeranthus hirtus and Clerodendrum inerme) used as anti-hypoglycaemic agent. Highest level of chromium $(5.434 \mu \mathrm{g} / \mathrm{g} \pm 3.50 \%)$ and cadmium $(1.900 \mu \mathrm{g} / \mathrm{g} \pm 0.60 \%)$ was reported in Pongamia glabra and Eugenia jambolana respectively, exceeded the WHO Limits. Other two lethal metals $\mathrm{Zn}(18.90 \mu \mathrm{g} / \mathrm{g} \pm 2.00 \%)$ and $\mathrm{Pb}(1.607 \mu \mathrm{g} / \mathrm{g} \pm 0.16 \%)$ in Momordica charantia and Eugenia jambolana respectively were recorded in permissible limit. It is suggested that stringent quality control system should be put in place to check the heavy metal contamination for avoidance of health hazard and ensuring the safe consumption.
\end{abstract}

Key words: heavy metal, hypoglycaemic, WHO, Quality control

\section{Introduction}

Diabetes is a common disease now a day's affecting large numbers of population globally. An estimated 422 million adults have been diagnosed with diabetes in 2014 and the numbers is projected to rise to 642 million by 2040 (WHO, 2016). The utilization of medicinal plants for curative purpose tends to extend over the years throughout the world due to their apparent effectiveness, low cost and no or less side effects (Viegas et al., 2006; WHO, 2004). Previous study estimated $65-80 \%$ of the world population depending on traditional herbal medicine as their primary health management (WHO, 1998). However, the utilization of aromatic and medicinal plants (AMPs) has come under scrutiny due to their observed toxicity among other concerns (WHO, 2004). Medicinal plants has pharmacologically active group like synthetic drugs authoritative for the required therapeutic effect in the body. Plants are highly reactive towards immediate environment and potentially lump various metals in their different parts which can alter the physiochemical properties of the plant (Behera et al., 2016; Zahra et al., 2016). The environmental influence of toxic metal contamination related to health issues remain a great area of affliction. Trace amounts of some toxic metal are favourable to human health but their presence exceeding estimated daily safe intake is harmful leading to physiological degradation and cell poisoning (Begum et al., 2017; Khan et al., 2008). The ability to deposit high concentration of metals than in the eco-system due to bio accumulation in plants escalated their injurious effect (Begum et al., 2017). High intake/ use of Lead (Pb) can cause high blood pressure (BP) and extensive weakening effects to the organs (Begum et al., 2017). Cadmium (Cd) accumulation is associated with renal and respiratory damages as well as kidney injury etc. Likewise Chromium (Cr) has been found to cause skin rashes, liver damage and lungs cancer. Studies have reported Nickel as carcinogen and subsequent adverse effect on lungs. also excessive amount of essential metal like zinc ( $\mathrm{Zn})$ and iron (Fe) has been found harmful causing vomiting and abdominal difficulties respectively (Adnan et al., 2014; Mustapha et al., 2016; Nkansah et al., 2016).Several works have been reported earlier on contaminatedMedicinal plants with heavy metals (Dghaim et al., 2015). Limited information is available about safe threshold level of heavy metals in traditional herbal plants.

The current study aims to diagnose the concentration of heavy metals in some commonly used anti diabetic medicinal plants in reference to worldwide standard permissible limits.

\section{Materials and Methods}

System suitability was checked by analysing blank sample to ensure the reliability of the results. The entire plant samples materials were acquired from the local market of Karachi, Pakistan, authenticated at Department of Botany, University of Karachi, Pakistan. Calibration standards were obtained by diluting the standards stock solutions of high concentration (1000ppm). All samples were extracted following the prescribed procedure of AOAC, 1990 and Wiersman and Ven, 1986. Metals analysis was performed on atomic absorption spectrophotometer (AAS Hitachi Z 8000) coupled with graphite tube analyser (GTA) and wet digestion method reported by AOAC (AOAC, 1990).

\section{Results and discussion}

World health organization (WHO) reported that $80 \%$ of the world population used plant based medication for their primary health care and enlisted 21000 plant species used directly or indirectly as medicine throughout the world (WHO, 
Pakistan Journal of Chemistry

1998; Seth and Sharma, 2004). Most of these medicinal plants are wild while some are properly cultivated. Plant based medication are generally thought to be free from side effects and cheap but presence of lethal metal in these material causes severe health problems (Hussain et al., 2014; Kulhari et al., 2013). Plant absorbs water, deposit different metals and both essential and non essential metals from soil in their various parts. Medicinal plants have active groups like other synthetic drugs which are contaminated with toxins, Heavy metals and pesticide residues etc. (Cereda and Mattos, 1996). The general perception about the medicinal plants and the drugs formulated from these natural sources to be safe, leads to the indiscriminate use of these products. Moreover, in some cases medicinal plants can have side effects like other synthetic drugs (WHO, 2004; Lanini et al., 2009). World Health Organization reports suggested that herbal plant and their formulated remedies should be analysed for toxin and HMs both qualitatively and quantitatively by setting benchmarks permissible levels (WHO, 2004; Annan et al., 2013; Singh et al., 2014). Limits for the analysed lethal metals were shown in the Table 1 given below.

Chen et al. (2005) reported the existence of various lethal metals in 42 Chinese medicinal plants in 2005, concentration of heavy metals $(\mathrm{Cd}, \mathrm{Pb} \& \mathrm{Hg})$ among selected $\mathrm{MP}$ were found slightly above the permissible limit.

Cadmium, lead, arsenic and mercury are considered the most toxic metals responsible for human poisoning (Begum et al., 2017; Maobe et al., 2012). Therefore it is recommended that medicinal plants and their remedies may be investigated for lethal metals concentration. Essential metal also causes injuries if taken in higher concentration, Sudha and Vivek (2014) reported high concentration of $\mathrm{Zn}$ and $\mathrm{Cu}$ in Ceropegia juncea.

Plants absorbed minerals and heavy and essential metals in varying concentrations depend upon their rate of transportation from soil \& water, deposit it in various parts for their sustainability but higher concentration of these metals is toxic to most of the plants. Presented study was organized to determine the toxic metal concentration in selected Antidiabetic medicinal plants used as herbal medication by the local residents. The amount of Lead, Cadmium, Chromium, and Zinc in medicinal plants (Adiantum capillus-veneris, Momordica charantia, Eugenia jambolana, Gymnema sylvestre, Allium sativum, Trigonella foenum-graecum, Pongamia glabra, Sphaeranthus hirtus and Clerodendrom inerme) extracted in water and acid (mention its name and concentration) are given in Table $(3,4)$ and Fig. $(1,2)$.

$\mathrm{Zn}$ is essential trace metal having a vital role in various cell actions like normal growth, brain development, behavioral response and wound healing (Maobe et al., 2012). $\mathrm{Zn}$ is the main component of many plant proteins and matello- enzyme specifically the enzyme which plays an important role in nucleic acid metabolism but large quantity of $\mathrm{Zn}$ can be injurious and responsible for $\mathrm{Zn}$ toxicity. $\mathrm{Zn}$ intoxication causes the same symptom of illness as lead does such as nausea, vomiting, diarrhea, fever and laziness.

In present study Momordica charantia $(18.90 \mu \mathrm{g} / \mathrm{g} \pm 2.00 \%)$ contained the highest amount of zinc followed by Allium sativum $(17.05 \mu \mathrm{g} / \mathrm{g} \pm 0.30 \%)$ while in Pongamia glabra leaf $(14.82 \mu \mathrm{g} / \mathrm{g} \pm 2.70 \%)$, Adiantum capillus-veneris $(6.225 \mu \mathrm{g} / \mathrm{g}$ $\pm 2.40 \%)$, Eugenia jambolana (4.525 $\mu \mathrm{g} / \mathrm{g} \pm 0.60 \%)$, Gymnema sylvestre $(11.57 \mu \mathrm{g} / \mathrm{g} \pm 1.70 \%)$, Sphaeranthus hirtus $(7.975$ $\mu \mathrm{g} / \mathrm{g} \pm 0.00 \% \mu \mathrm{g} / \mathrm{g})$, Clerodendrom inerme $(5.800 \mu \mathrm{g} / \mathrm{g} \pm 0.40 \%)$ while the least concentration found were in the seed of Trigonella foenum-graecum $(1.600 \mu \mathrm{g} / \mathrm{g} \pm 3.10 \%)$. The amount of the trace metal were determined within the permissible level of WHO (Table 1). Contrary to the investigation of Hussain et al. (2006) who reported the maximum value for $\mathrm{Zn}$ $5.21 \mathrm{mg} / \mathrm{Kg}$ in the leaves of $D$. alba our result were relatively high.

Zinc is one of the most important nutrient present 85 percent in muscle and bones $11 \%$ in skin and liver tissue while rest in other body tissues (Tapiero and Tew, 2003). Its deficiency causes the loss of sensitivity (touch and smell) and excess causes abdominal pain, nausea, vomiting and diarrhoea.

$\mathrm{Cr}$ is considered among one of the highly toxic element in the world released by tanneries, steel industries and sewage sludge executions along with alloys in motor vehicles. The biological activity of chromium depends on its electronic state (Valence state) and complexes it forms like $\mathrm{Cr}^{+3}$ is required for the optimal glucose uptake by cells. Cr regulates insulin and blood glucose while their deficiency increases the blood glucose which may lead to the development of diabetes. Chromium uptakes of 5-30 $\mu \mathrm{g} / \mathrm{g}$ are considered lethal for the plant as it causes depletion in plant growth and yield.

The permissible level for Chromium in raw and finished plant products given by WHO indicates that among all the samples tested three species i.e. (Eugenia jambolana $0.724 \mu \mathrm{g} / \mathrm{g} \pm 4.70 \%$, Momordica charantia $1.811 \mu \mathrm{g} / \mathrm{g} \pm 2.40 \%$, Allium sativum $1.811 \mu \mathrm{g} / \mathrm{g} \pm 0.60 \%$ contained the element relatively smaller than the limit. However, the remaining species (Adiantum capillus-veneris, Gymnema sylvestre, Trigonella foenum-graecum, Pongamia glabra, Sphaeranthus hirtus and Clerodendrom inerme) had concentration of $\mathrm{Cr}$ almost two times higher than WHO limit (Table- 3). Similar results were recorded by Kulhari et al. (2013) as they reported only one plant having Cr concentration within the standard permissible limit set by World health organization.

$\mathrm{Cr}$ is an important element required for the normal glucose metabolism and insulation production in pancreas. However, toxic effects of Chromium intake causes severe injuries like nose irritations, skin rash, bleeding, stomach, liver kidney, lung and nasal itch damages. Also, in $\mathrm{Cr}^{+4}$ valance state its behavior has been observed to have carcinogenic causing lung cancer (Khan et al., 2008). 
Cadmium (Cd) too is toxic metal which can inversely affect the plant production at the amount ranging from 5-30 $\mu \mathrm{g} / \mathrm{g}$ (Kulhari et al., 2013). In recent years prevalent cadmium accumulation in water, dietary products, soil, milk, herbal plant and their remedies has raised concerns among researchers (Kulhari et al., 2013). The main sources of guiding cadmium deposition to plants and soil are phosphate fertilizers, smelters (non-ferrous), mines of lead and zinc, sewage sludge utilization and combustion of fossil fuels. High concentration of cadmium reduces calcium absorption, which results in Itai-Itai disease showing signs such as non stiffening of skeleton, anemia, renal damage and eventually death (Singh et al., 2014). Cadmium accumulation in the body replaces zinc ( $\mathrm{Zn}$ ) biochemically causing hypertension.

In current study, all tested samples were analysed for cadmium concentration. Among all the species, Adiantum capillusveneris, Eugenia jambolana, Gymnema sylvestre, Allium sativum possessed 2-4 times higher level of the recommended permissible limit. Whereas the levels of cadmium analysed were below the minimum detectable range for Trigonella foenum-graecum, Pongamia glabra. Similar results were reported by Annan et al. (2013) who found all the collected samples with Cd concentration exceeding the WHO threshold level. However, Begum et al. (2017); Sindu and Beena (2016) and Maobe et al. (2012) reported all tested samples within permissible limit set by WHO.

Intoxication of Cadmium above tolerable limit may result both kind of poisoning (acute and chronic) like irreversible damages of kidney, liver, vascular and immune system (Jabeen et al., 2010).

Lead $(\mathrm{Pb})$ is the most common and abundant heavy metal existing in the environment. Lead is considered perilous to animal, plants and micro-organism. The nonstop usage of fertilizer, fuel combustion and sewage sludge are the major sources of rising lead concentration (Kulhari et al., 2013). Lead is non-essential metal incorporated into the body by ingestion, inhalation causes serious body poisoning like heart, kidney, nerves, blood, generative and digestive system (Zheljazkov and Jekov., 1995: Khan et al., 2007 ). Fatal doses of the lead stimulating serious diseases leading to permanent difficulties with cerebrals issues (Begum et al., 2017). Their poisonous causes nuisance, anemia, stomach pain and irritability. In critical situations, it may cause seizure, coma and even death (Bellinger, 2008; Singh et al., 2014).The plant tissues tested (stem, leaves, fruit, seed, cloves) contained remarkably lower concentration of lead compared to the permissible level of world health organization.

Maximum amount of lead was found $1.607 \pm 0.16 \%(\mu \mathrm{g} / \mathrm{g})$ in Eugenia jambolana. the lead $(\mathrm{Pb})$ content in Adiantum capillus-veneris was $0.712 \mu \mathrm{g} / \mathrm{g} \pm 0.63 \%$, Momordica charantia $0.501 \mu \mathrm{g} / \mathrm{g} \pm 0.25 \%$, Gymnema sylvestre $0.518 \mu \mathrm{g} / \mathrm{g}$ $\pm 0.49 \%$, Allium sativum $0.725 \mu \mathrm{g} / \mathrm{g} \pm 0.20 \%$, Trigonella foenum-graecum $0.754 \mu \mathrm{g} / \mathrm{g} \pm 0.64 \%$, Pongamia glabra 0.214 $\mu \mathrm{g} / \mathrm{g} \pm 0.47 \%$, Sphaeranthus hirtus $0.451 \mu \mathrm{g} / \mathrm{g} \pm 0.10 \%$ and $0.183 \mu \mathrm{g} / \mathrm{g} \pm 0.72 \%$ for Clerodendrom inerme. The permissible limit of lead revealed that all medicinal plant carries fewer amounts than permissible (Table 1).The level of $\mathrm{Pb}$ below permissible limit recommending that toxicity could be rise from long term exercise/application of these plants. Our results corroborated with those of Begumet al. (2017) and Sindu and Beena (2016) who reported less concentration of lead comparable to the global standards.

Lead can cause high blood pressure and excessive weakening effects to the organs, mostly affects the central nervous system. The typical symptoms of lead intoxication are nausea, headache, fatigue, and anemia (Khan et al., 2008).

\section{Conclusion}

Medicinal plants are the sources of active ingredients, used to cure diseases varying from acute coryza (common cold) to genetic disorder. However continuous environmental pollution leads to the accumulation of heavy metals $(\mathrm{Pb}, \mathrm{Cd}, \mathrm{As}$, $\mathrm{Hg}$ ) in soil, water and ultimately to our food chain. In most of the cases, water extracts of the herbs are taken for the treatment of ailment but few are taken as whole (e.g. Momordica charantia and Eugenia jambolana). Metals from these medicinal plant may be extracted during acid digestion in stomach, therefore in parallel to the water extract acid digested samples were also taken for evaluation of the total heavy metal contents in selected medicinal plants. Our study indicated that the value of Chromium and Cadmium were slight above the permissible limit and might become chronically dangerous. Therefore it is strongly recommended that medicinal herbs for the production of herbal medicine should be harvested and collected from non contaminated areas. On the basis of our study it is suggested that there should be strict and stringent quality control system to check the heavy metal contamination in medicinal plant or part of plant used for various diseases to assure the safety aspects concerned human consumption.

\section{Refrences}

1. M. Adnan, R. Bibi, S. Mussarat, A. TariqandZ. K. Shinwari, Ethnomedicinal and phytochemical review of Pakistani medicinal plants used as antibacterial agents against Escherichia coli. Annals of clinical microbiology and antimicrobials, 13, 40(2014).

2. K. Annan, R. A. Dickson, I. K. Amponsah and I. K. Nooni,The heavy metal contents of some selected medicinal plants sampled from different geographical locations. Pharmacognosy research, 5, 103-108 (2013). 
Pakistan Journal of Chemistry

3. AOAC. 1990. Official methods of analysis of the AOAC, 15th ed. Association of official

a. analytical chemists. Arlington, VA, USA.

4. H. A. Begum, M. Hamayun, K. Zaman, Z. K. Shinwari andA. Hussain, Heavy metal analysis in frequently consumable medicinal plants of Khyber Paktunkhwa, Pakistan. Pak. J. Bot., 49, 1155-1160. (2017).

5. B. BeheraandS. Bhattacharya, The importance of assessing heavy metals in medicinal herbs: a quantitative study. TANG., 6, 37-40, (2016).

6. D. C. Bellinger, Very low lead exposures and children's neurodevelopment. Current opinion in pediatrics., 20, 172-177,(2008).

7. M. Cereda, , andM. Mattos, Linamarin: the toxic compound of cassava. Journal of venomous animals and toxins., 2, 06-12,(1996).

8. Y. Chen, ,C. Wang, and Z. Wang, Residues and source identification of persistent organic pollutants in farmland soils irrigated by effluents from biological treatment plants. Environment international., 31, 778-783(2005).

9. C. A. Commission, Contaminants, Joint FAO/WHO Food standards Program (17). Geneva: Codex Alimentarious. Contam Toxicol., 76: 163-170 (1984).

10. R. Dghaim, S. Al Khatib, H. RasoolandM. Ali Khan, Determination of heavy metals concentration in traditional herbs commonly consumed in the United Arab Emirates, Journal of environmental and public health., (2015).

11. FAO/WHO, Contaminants. In Codex Alimentarius, vol. XVII, Edition 1. FAO/WHO,

a. Codex AlimentariusCommision, Rome (1984).

12. F. Hussain, I. Khan, L. Khanand Wali-Ullah. Determination of heavy metals in medicinal plants,Journal of the Chemical Society of Pakistan., 28, 347-351,(2006).

13. J. Hussain, N. Rehman, Z. K. Shinwari, A. L Khan, A. Al-Harrasi , L. AliandF. Mabood,Preliminary comparative analysis of four botanicals used in the traditional medicines of Pakistan. Pak. J. Bot., 46, 1403-1407( 2014).

14. S. Jabeen, M.T. Shah, S. KhanandM. Q Hayat, Determination of major and trace elements in ten important folk therapeutic plants of Haripur basin, Pakistan,Journal of Medicinal Plants Research., 4, 559-566, (2010).

15. V. F. V. Junior, A. C. PintoandM. A. M. Maciel, Plantas medicinais: cura segura. Química nova., 28, 519-528, (2005).

16. M. A. Khan, I. Ahmad andI. U. Rahman, Effect of environmental pollution on heavy metals content of Withania somnifera,Journal of the Chinese Chemical Society.,54, 339-343 (2007).

17. S. A. Khan, L. Khan, I. Hussain, K. B. Marwat andN. Akhtar, Profile of heavy metals in selected medicinal plants. Pakistan Journal of Weed Science Research., 14(1-2), 101-110,(2008).

18. Kulhari, A. Sheorayan, S. Bajar, S. Sarkar, A. Chaudhury andR. K. Kalia, Investigation of heavy metals in frequently utilized medicinal plants collected from environmentally diverse locations of north western India. SpringerPlus.,2, 676, (2013).

19. J. Lanini, J. M. Duarte-Almeida, S. Nappoand E. A Carlini, " Natural and therefore free of risks": adverse effects, poisonings and other problems related to medicinal herbs by" raizeiros" in Diadema/SP,Revista Brasileira de Farmacognosia., 19, 121-129, (2009).

20. M. A. Maobe, E. Gatebe, L. GituandH. Rotich, Profile of heavy metals in selected medicinal plants used for the treatment of diabetes, malaria and pneumonia in Kisii Region, Southwest Kenya. Global Journal of pharmacology., 6, 245-251 (2012).

21. B. Mustapha, D. Kubmarawa, M. ShagalandA. Hayatudeen, Heavy Metal Profiles of Medicinal Plants Found within the Vicinity of Quarry Site in Demsa, Adamawa State, Nigeria. British J. App. Sci. \& Technol., 13, 1-6, (2016).

22. M. A. Nkansah, S. T. Hayford, L. S. Borquaye andJ. H. Ephraim, Heavy metal contents of some medicinal herbs from Kumasi, Ghana, Cogent Environmental Science., 2, 1234660, (2016).

23. S. Seth and B. Sharma, Medicinal plants in India, Indian J Med Res., 120, 9-11(2004).

24. S. Sindhu and C. Beena, Quantification of heavy metals in the Aloe vera L. samples available in the market,South Indian Journal of Biological Sciences., 2, 81- 83(2016).

25. K. P. Singh, S. Bhattacharya andP. Sharma, Assessment of heavy metal contents of some Indian medicinal plants. American-Eurasian J Agric Environ Sci, 14, 1125-1129, (2014).

26. K.B. Sudhaand C. Vivek, Heavy metal analysis fromtraditionally used herb Ceropegia juncea (Roxb.) IOSR J.Pharm., 4: 07-11, (2014).

27. H. TapieroandK. D. Tew, Trace elements in human physiology and pathology: zinc and metallothioneins, Biomedicine \& Pharmacotherapy., 57, 399-411, (2003).

28. Jr. C.Viegas, V. d. S. Bolzani andE. J. Barreiro, Os produtos naturais e a química medicinal moderna, Química nova., 326-337, (2006).. 
29. WHO, Quality control methods for medicinal plant materials. World health organization, Genava (1998).

30. WHO, WHO guidelines on safety monitoring of herbal medicines in pharmacovigilance systems. World health organization, Genava(2004).

31. WHO, Global report on diabetes: World health organization, Genava (2016).

32. D. Wiermans and B.Ven, Cadmium, lead, mercury and arsenic concentration in crops and corresponding soil in Netherlands. J Agric. Food Chem., 34, 1067 (1986).

33. N. B. Zahra, Z. K. Shinwari and M. Qaiser, DNA barcoding: a tool for standardization of Herbal Medicinal Products (HMPS) of Lamiaceae From Pakistan. Pakistan Journal of Botany., 48, 2167-2174,(2016).

34. V. Zheljazkov and D. Jekov, Heavy metal content in some essential oils and plant extracts. Paper presented at the International Symposium on Medicinal and Aromatic Plants 426, (1995). 
Pakistan Journal of Chemistry

Table 1. Permissible Limits (WHO) of Toxic Metals [4, 23].

\begin{tabular}{lcll}
\hline $\mathbf{Z n}$ & $\mathbf{C r}$ & $\mathbf{C d}$ & $\mathbf{P b}$ \\
\hline 27.40 & 2.00 & 0.30 & 10.00 \\
\hline Finished Herbal material (mg/day) & & 0.02 \\
\hline- & 0.02 & 0.006 & \\
\hline
\end{tabular}

Table 2. Plants Sample Collected from the Market.

\begin{tabular}{llll}
\hline \multicolumn{1}{c}{ Botanical name } & Common name & Family & Part of the plant \\
\hline Adiantum capillus-veneris & Avenca & Pteridaceae & $\mathrm{S}$ \\
Momordica charantia & Bitter Melon & Cucurbitaceae & $\mathrm{F}$ \\
Eugenia jambolana & Jambul Seeds & Myrtaceae & $\mathrm{S}^{*}$ \\
Gymnema sylvestre & Gurmar & Asclepiadaceae & $\mathrm{L}$ \\
Allium sativum & Garlic & Amaryllidaceae & $\mathrm{C}$ \\
Trigonella foenum-graecum & Fenugreek & Fabaceae & $\mathrm{S}^{*}$ \\
Pongamia glabra & Karanjwa & Leguminaceae & $\mathrm{S}^{*}$ \\
Sphaeranthus hirtus & Paneer herb & Asteracea & $\mathrm{L}+\mathrm{F}$ \\
Clerodendrom inerme & Dum Dum & Verbenaceae & $\mathrm{L}$ \\
\hline
\end{tabular}

Stems, F=Fruits, $\mathrm{L}=$ Leaves, $\mathrm{C}=$ Cloves $\mathrm{S}^{*}=$ Seed

Table 3. Concentration $(\mu \mathrm{g} / \mathrm{g})$ of heavy metals in selected medicinal plants extracted in water.

\begin{tabular}{lllll}
\hline \multicolumn{1}{c}{ Medicinal Plant } & $\mathbf{Z n}$ & $\mathbf{C r}$ & $\mathbf{C d}$ & $\mathbf{P b}$ \\
\hline Adiantum capillus-veneris & $6.225 \pm 2.40 \%$ & $2.536 \pm 0.80 \%$ & $1.200 \pm 1.90 \%$ & $0.712 \pm 0.63 \%$ \\
Momardica charantia & $18.90 \pm 2.00 \%$ & $1.811 \pm 2.40 \%$ & $0.250 \pm 1.30 \%$ & $0.501 \pm 0.25 \%$ \\
Eugenia jambolana & $4.525 \pm 0.60 \%$ & $0.724 \pm 4.70 \%$ & $1.900 \pm 0.60 \%$ & $1.607 \pm 0.16 \%$ \\
Gymnema sylvestre & $11.57 \pm 1.70 \%$ & $2.536 \pm 2.00 \%$ & $0.600 \pm 0.70 \%$ & $0.518 \pm 0.49 \%$ \\
Allium sativum & $17.05 \pm 0.30$ & $1.811 \pm 0.60 \%$ & $0.620 \pm 0.60 \%$ & $0.725 \pm 0.20 \%$ \\
Trigonella foenum-graecum & $1.600 \pm 3.10 \%$ & $2.536 \pm 1.50 \%$ & $\mathrm{ND}$ & $0.754 \pm 0.64 \%$ \\
Pongamia glabra & $14.82 \pm 2.70 \%$ & $5.434 \pm 3.50 \%$ & $\mathrm{ND}$ & $0.214 \pm 0.47 \%$ \\
Sphaeranthus hirtus & $7.975 \pm 0.00 \%$ & $4.347 \pm 2.30 \%$ & $0.200 \pm 2.80 \%$ & $0.451 \pm 0.10 \%$ \\
Clerodendrom inerme & $5.800 \pm 0.40 \%$ & $5.253 \pm 0.40 \%$ & $0.200 \pm 1.20 \%$ & $0.183 \pm 0.72 \%$ \\
\hline
\end{tabular}

$\mathrm{ND}=$ not detected

Table 4. Concentration $(\mu \mathrm{g} / \mathrm{g})$ of heavy metals in selected medicinal plants extracted in acid.

\begin{tabular}{lllll}
\hline \multicolumn{1}{c}{ Medicinal Plant } & $\mathbf{Z n}$ & $\mathbf{C r}$ & $\mathbf{C d}$ & Pb \\
\hline Adiantum capillus-veneris & $62.00 \pm 1.60 \%$ & $9.225 \pm 0.50 \%$ & $6.00 \pm 1.70 \%$ & $6.00 \pm 0.50 \%$ \\
Momardica charantia & $72.25 \pm 2.40 \%$ & $6.975 \pm 0.40 \%$ & $3.00 \pm 2.90 \%$ & $3.50 \pm 4.90 \%$ \\
Eugenia jambolana & $27.75 \pm 0.90 \%$ & $6.100 \pm 0.40 \%$ & $2.50 \pm 1.20 \%$ & $3.25 \pm 1.00 \%$ \\
Gymnema sylvestre & $107.0 \pm 0.70 \%$ & $2.003 \pm 2.00 \%$ & $3.30 \pm 1.30 \%$ & $4.50 \pm 3.10 \%$ \\
Allium sativum & $57.25 \pm 0.90 \%$ & $6.175 \pm 1.20 \%$ & $1.50 \pm .250 \%$ & $0.30 \pm 1.50 \%$ \\
Trigonella foenum-graecum & $110.75 \pm 2.90 \%$ & $2.268 \pm 1.80 \%$ & $0.20 \pm .0 .20 \%$ & $15.50 \pm 1.74 \%$ \\
Pongamia glabra & $96.75 \pm 2.70 \%$ & $1.233 \pm 1.00 \%$ & $0.30 \pm .1 .10 \%$ & $0.75 \pm 2.35 \%$ \\
Sphaeranthus hirtus & $68.00 \pm 4.40 \%$ & $1.193 \pm 4.20 \%$ & $0.80 \pm 1.30 \%$ & $4.25 \pm 4.10 \%$ \\
Clerodendrom inerme & $69.00 \pm 0.40 \%$ & $1.008 \pm 0.70 \%$ & $0.95 \pm 1.30 \%$ & $5.00 \pm 2.50 \%$ \\
\hline
\end{tabular}




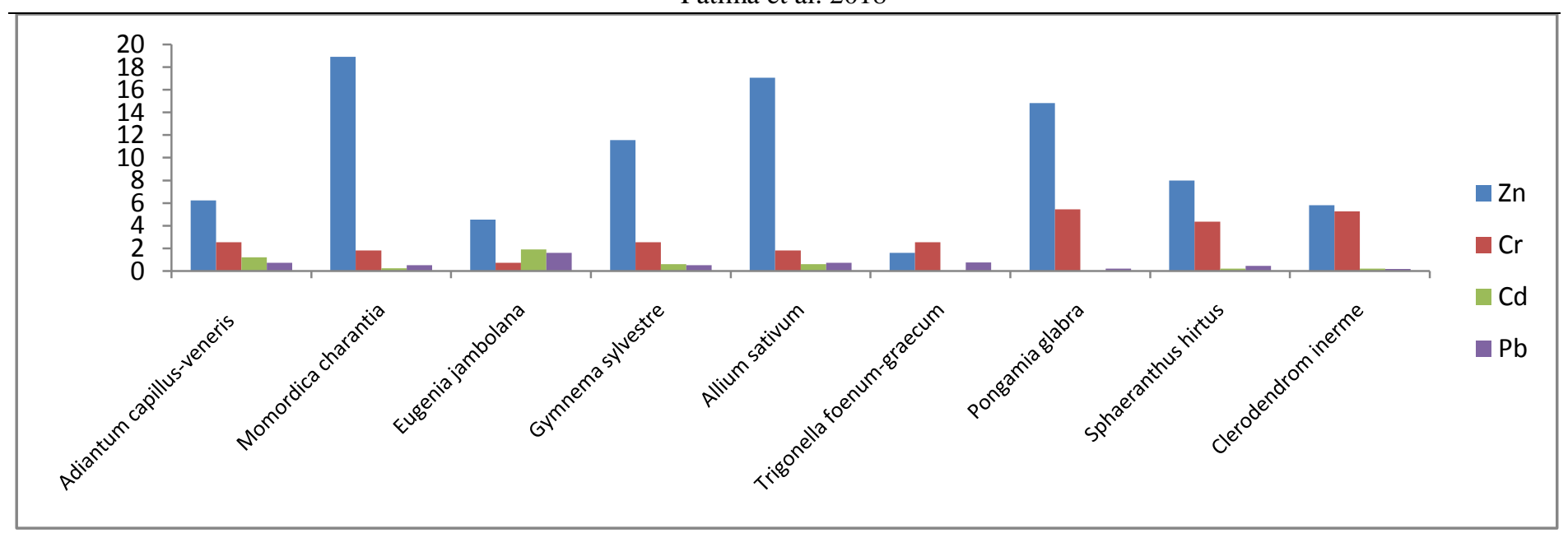

Fig 1. Concentration of HMs in selected medicinal plants extracted in water.

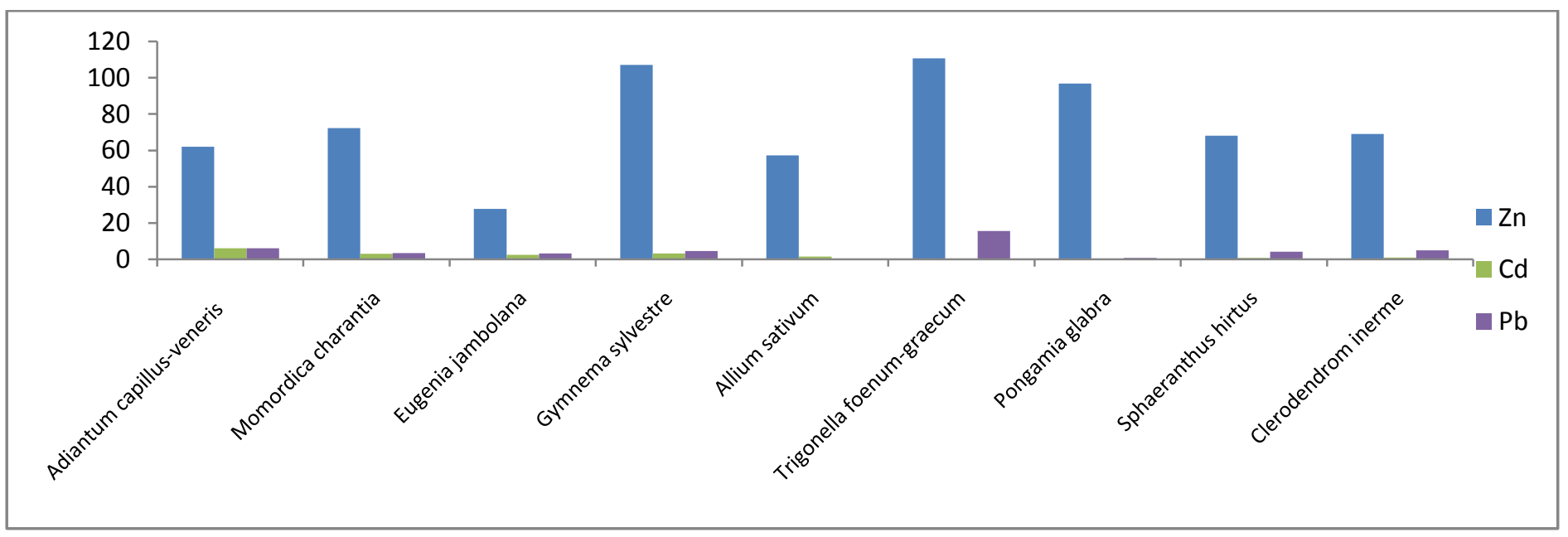

Fig 2. Concentration of various HMs in selected medicinal plants extracted in Acid 